\title{
Development of a benthic macroinvertebrate biotic index to evaluate wetland health in Northeastern Thailand
}

\author{
Alongkorn Phaphong ${ }^{1}$ and Narumon Sangpradub ${ }^{2 *}$ \\ ${ }^{1}$ Department of Biology, Faculty of Science, Khon Kaen University, Thailand. \\ ${ }^{2}$ Applied Taxonomic Research Center, Department of Biology, Faculty of Science, Khon Kaen University, Thailand. \\ Accepted 8 November, 2012
}

\begin{abstract}
The aim of this study was to identify appropriate biometric candidates for assessing the environmental quality of wetlands in northeastern Thailand. Field sampling was conducted in 13 wetlands during the cool season of 2009 and hot season of 2010. Macroinvertebrates were collected based on the proportion of multi-habitats using a $500 \mu \mathrm{m}$ D-frame dip net within a $500 \mathrm{~m}$ reach. Fourteen physicochemical parameters of the environmental quality were measured. The total scores of the human disturbance score for the reference sites were lower than those for the test sites, and the number of total taxa of macroinvertebrates in the reference sites was higher than the numbers of taxa in the test sites in both seasons. The $\mathrm{BOD}_{5}, \mathrm{PO}^{3-}$, conductivity and turbidity were significantly different between the reference and test sites $(p<0.05)$. The 63 test metrics, only 7 core metrics for the biological index score were included in the biotic index. The results revealed that the index can be used for all three wetland types in northeastern Thailand. However, the score must be tested and calibrated for other ecoregions.
\end{abstract}

Key words: Benthic macroinvertebrates, biotic index, bioassessment, multi-metric index, wetland, Northeastern Thailand.

\section{INTRODUCTION}

A large number of wetlands in Thailand have been lost or are rapidly and progressively being degraded by obvious and/or obscure causes (OEPP, 2002). The loss of wetland area is a continuous trend because of the growing amount of disturbance due to urbanization and the extension of roads and other infrastructure into rural areas. Wetland hydrology also is significantly affected by the removal of vegetation, increased impervious surfaces, the installation of storm drainage systems, the construction of roads and bridges, all of which can decrease the depth of wetlands and block the migration of aquatic animals (OEPP, 2002). Over the past decade,

${ }^{\star}$ Corresponding author. E-mail: narumon@kku.ac.th bioassessment methods have been increasingly used to quantify the anthropogenic impairment of wetland ecosystems, such as the Indexes of Biotic Integrity (IBIs) (Kerans and Karr, 1994) these indices could be used to assess lotic systems and to monitor the environmental quality of streams and rivers throughout the world (Reynoldson et al., 1995; Barbour et al., 1999; Smith et al., 1999; Mustow, 2002; Morse et al., 2007).

The body of literature for wetland bioassessment protocols using benthic macroinvertebrates is small and centered almost entirely on research conducted in the USA (U.S.EPA, 2002) and Australia (Davis et al., 2006). The majority of the published findings in the literature suggest that benthic macroinvertebrates are a beneficial tool for the biological assessment of wetlands but that the indices need to be modified (Wilcox et al., 2002; Chipps 


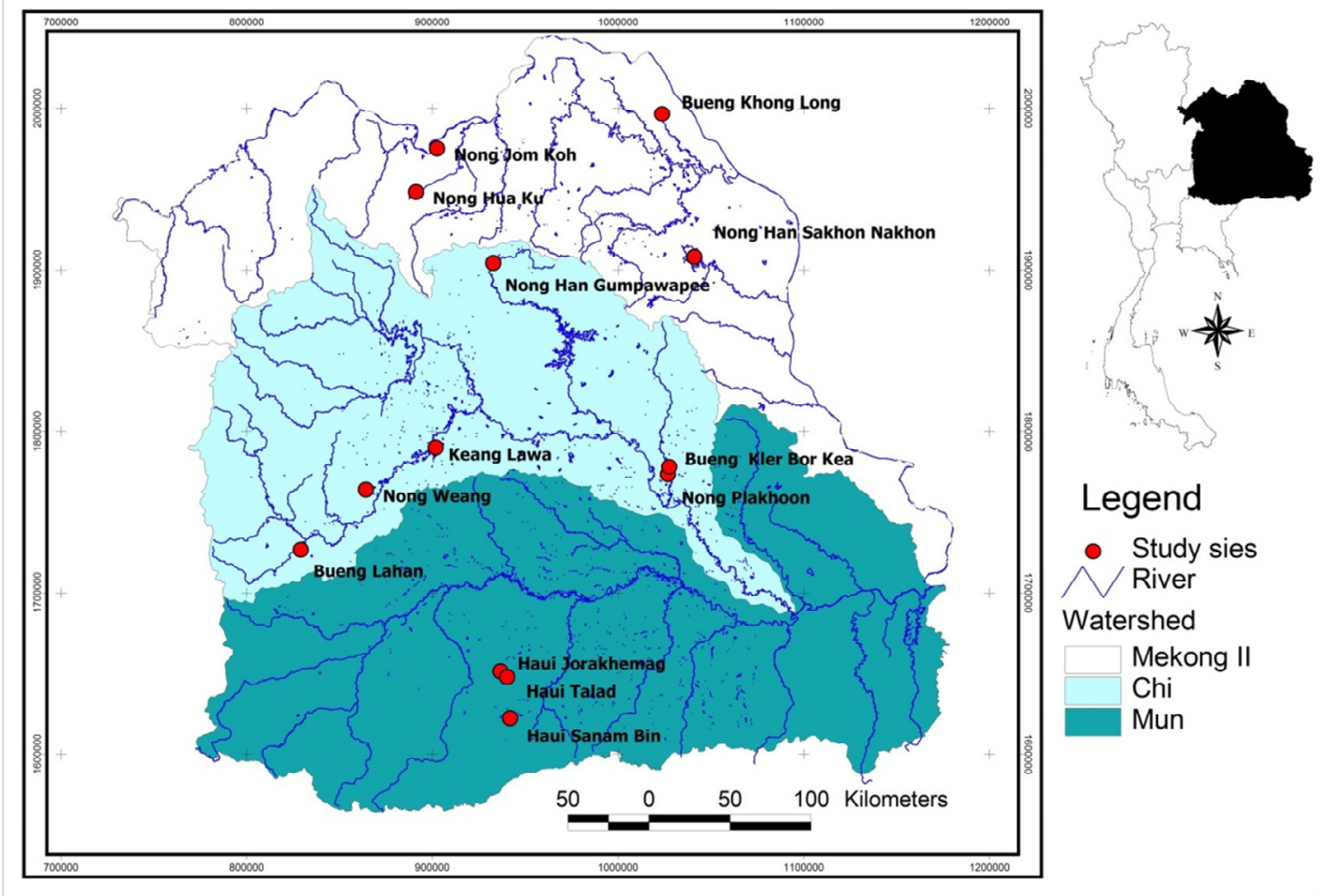

Figure 1. Map of study area showing the distribution of 13 sampling sites in northeast Thailand

et al., 2006; Marchetti et al., 2008). Many studies show that the structure of the benthic macroinvertebrate communities in wetlands is complex and depends on many factors, such as the vegetation structure, hydroperiod, water body area, food resources and water chemistry (Battle and Golladay, 1999; Heino, 2000; Kazancl et al., 2003; Tarr et al., 2005; Galbrand et al., 2007; Studinski and Grubbs, 2007). Additional problems include the limited number of comparable sites, the potential lack of undisturbed reference sites, and the variable effects of different disturbance types (Wilcox et al., 2002).

Currently, there are few studies regarding the development of indexes for wetlands based on the benthic macroinvertebrates (Burton et al., 1999; Kashian and Burton, 2000; Blocksom et al., 2002; Yimer and Mengistou, 2009). The wetlands in Thailand comprise an area of $36,616.16$ square kilometers, which is approximately $7.5 \%$ of the total area of the country, and there are a wide range of riverine, lacustrine, palustrine and coastal ecosystems. The Office of Environmental Policy and Planning (OEPP) in Thailand identified the importance of wetlands based on the criteria of the Convention on Wetlands (Ramsar Convention) at 3 levels: international, national and local (OEPP, 2002). The current water quality assessment tools based on macroinvertebrate parameters, which have been extensively reviewed in the literature, are already in use to assess the ecological quality of streams and rivers in Thailand (Thorne and Williams, 1997; Mustow, 2002; Boonsoong et al., 2009; Getwongsa et al., 2010, Uttaruk et al., 2011), yet there are currently no working macroinvertebrate assessment systems for wetlands; indeed, the few studies addressing wetland monitoring have focused only on fish and birds (OEPP, 2002; Pagdee et al., 2007). Accordingly, the aim of this study was to develop a biotic index using benthic macroinvertebrates as a bioassessment tool for wetlands.

\section{MATERIALS AND METHODS}

\section{Study area and site selection}

This study was conducted in 13 wetlands, including 3 lakes, 6 marshes and 4 reservoirs (OEPP 2002), during the cool season of 2009 and the hot season of 2010 . The study sites were located at $14^{\circ} 38^{\prime}$ to $18^{\circ} 03^{\prime} \mathrm{N}$ and $101^{\circ} 50^{\prime}$ to $104^{\circ} 20^{\prime} \mathrm{E}$ in northeastern Thailand (Figure 1). The region consists of a tilted plateau, and the elevation varies from 130 to $220 \mathrm{~m}$ above sea level. The annual precipitation varies between 900 and $1000 \mathrm{~mm}$.

The annual average temperature ranges from 26 to $27^{\circ} \mathrm{C}$. The wetlands were categorized as being of international importance (7) and national importance (6) based on the criteria of high fish diversity and high bird diversity (OEPP, 2002). The sampling stations were chosen based on their accessibility and their natural and impaired condition. The reference sites represented the least impaired condition available, whereas the test sites were known to be influenced by various levels of anthropogenic stress factors and 
are generally utilized as both land and water resources. These sites were influenced by hydrologic modifications, such as ditching, filling and man-made dikes, and for vegetative modifications. The land utilization included rice cultivation, cropping, and livestock rearing.

\section{Water quality and habitat characteristic assessment}

Fourteen physicochemical parameters were measured and benthic macroinvertebrates were collected at each sampling site. The dissolved oxygen (DO, mg/L) and water temperature $\left({ }^{\circ} \mathrm{C}\right)$ were measured in situ using a YSI Dissolved Oxygen meter Model 57 and a Sension $\mathrm{TM}_{1}$ Portable $\mathrm{pH}$ meter, respectively. The conductivity $(\mu \mathrm{s} / \mathrm{cm})$ and Total Dissolved Solids (TDS, $\mathrm{mg} / \mathrm{L})$ were evaluated with Fisher Scientific method 09-326-2. The ammonianitrogen $\left(\mathrm{mg} / \mathrm{L} \mathrm{NH}{ }_{3}-\mathrm{N}\right.$, the Nessler method), nitrate-nitrogen $(\mathrm{mg} / \mathrm{L}$ $\mathrm{NO}_{3}-\mathrm{N}$, ascorbic acid method), orthophosphate (mg/L $\mathrm{PO}_{4}{ }^{3-}$, cadmium reduction method), Total Suspended Solids (TSS) (mg/L) and turbidity (FAU) were measured using a Hach DR/2010 spectrophotometer model 49300-00. The biochemical oxygen demand $\left(\mathrm{BOD}_{5}, \mathrm{mg} / \mathrm{L}\right)$ was assessed by the concentrations in a dark bottle after incubation at $20^{\circ} \mathrm{C}$. The chlorophyll a $(\mu \mathrm{g} / \mathrm{L})$ level was measured using a methanol extraction method (APHA AWWA WPCF, 1998). To evaluate the group of wetlands across a gradient of disturbances, we calculated a human disturbance score for each wetland based on the Main Rapid Assessment Method (U.S. EPA, 2003), with five subsections of impact: evidence of chemical pollutants, hydrologic modifications, impervious surface, non-point sources, and vegetative modifications. The final human disturbance score was the sum of the five subsections and ranged from 0 (not observed), representing an unimpacted site, to 125 , the highest possible score for each site, representing a severely impacted sited.

\section{Benthic macroinvertebrate sampling and processing}

Benthic macroinvertebrates were collected at each site using a multi-habitat approach with a D-frame dip net (500 $\mu \mathrm{m}$ mesh), sampling method was modified from Flotemersch et al. (2006). A total of 10 sweeps were conducted proportionately for all the major habitat types over a $500 \mathrm{~m}$ reach. The specimens collected in all 10 sweeps were combined into a single sample and preserved in $70 \%$ ethanol. The benthic macroinvertebrate samples were rinsed on a $500 \mu \mathrm{m}$ mesh sieve, and the large material was discarded. All of the organisms from the sorted sample were identified to the lowest possible taxonomical level, usually the genus or species. The identification was based on a reference text (Mose et al., 1994; Sangpradub and Boonsoong, 2006) and the individuals were assigned to operational taxonomic units (OTUs).

\section{Data analysis}

The multivariate analysis of the macroinvertebrate assemblages was performed using clustering and ordination (NMDS) methods in PC-ORD ver.5 (McCune and Mefford, 2006). The macroinvertebrate data were transformed to presence/absence. An independent-sample t-test was performed using the physicochemical data to test for differences between the reference and test sites. The overall metrics were calculated within the Ecological Data Application System (EDAS) (Tetra Tech, 2000a), and the candidate metrics were examined for membership and applicability as core metrics to assess the biological condition of the wetlands. The overall metric sensitivity was evaluated by comparing the values between the reference and test sites. Box and whisker plots were used to determine an appropriate suite of metrics that displayed a strong discriminatory power. Exclusion was based on the examination of the $25^{\text {th }}$ percentile, median, and $75^{\text {th }}$ percentile values of the reference site population for each metric. This comparison can be expressed numerically by its Discrimination Efficiency (DE) (Stribling et al., 2000). Pearson's correlation analysis was used to select the candidate metrics for the index; those metric combinations that resulted in correlation coefficients $>0.85$ were considered highly redundant. Only one of the metric from a group was selected and included in developing the final index.

Two metric scoring methods were used to develop the multimetric index; discrete scoring ( $D=$ Discrete, $R=$ Reference sites used to set expectation, $Q 1=25^{\text {th }}$ percentile of reference site used for expectation; DRQ1) and continuous scoring ( $C=$ Continuous, $\mathrm{A}=\mathrm{All}$ site used to set expectation, $\mathrm{U}=\mathrm{Upper}$ expectation set all sites only; CAU) methods (Blocksom, 2003). Scoring process for the first method, each metric was scored by creating a value range from the reference site population whereby a 1,3 and 5 points categorical scoring system was developed for each metric (Barbour et al., 1999). For the second method, the range of value for each metric was standardize on 100 point scale, assessing all metric value a score ranging from 0 (worst) to 100 (best) (Tetra Tech, 2000b). To summarize the multimetrics index to single numerical index value. All trial index were tested to find the metric combination that resulted in the greatest DEs.

\section{RESULTS}

\section{Physicochemical parameters and habitat characteristics}

The mean values of most of the physicochemical parameters were not significantly different between the reference and test sites (Table 1). The conductivity, $\mathrm{BOD}_{5}, \mathrm{PO}_{4}{ }^{3-}$ and turbidity were significantly higher at the test sites than the reference sites in both seasons $(p<$ 0.05). In hot season, the nitrate-nitrogen and TSS levels were significantly higher at the test sites than the reference sites, whereas the chlorophyll a content was significantly higher at the reference sites than at the test sites $(p<0.05)$.

The physical habitat structure of all of the reference sites had a good riparian zone and vegetative protection, whereas the riparian buffer and bank vegetation of the test sites were scarce due to human activities, such as urbanization, agriculture, the increased density of impervious surfaces and road construction.

The box plot analysis showed that the human disturbance score for the reference sites was lower (23 \pm $0.23,21 \pm 4.45$ ) than the scores for the test sites (44 \pm $0.23,44 \pm 10.64)$ for cool and hot season, respectively (Figure 2). The discriminatory power of the total human disturbance score in the cool season was stronger than in the hot season.

Pearson's correlation analysis revealed that 23 metrics were positively correlated $(r>0.32, p<0.01)$ with the total human disturbance score. The NMDS revealed ecologically interpretable patterns of the community structure of the benthic macroinvertebrates at the reference site (stress $=18.23$ ). The reference sites were aggregated into two major groups by season, indicating 
Table 1. Mean \pm SD of physicochemical parameters in reference and test sites in the cool and hot seasons.

\begin{tabular}{|c|c|c|c|c|c|c|}
\hline \multirow{2}{*}{ Parameter } & \multicolumn{3}{|c|}{ Cool season } & \multicolumn{3}{|c|}{ Hot season } \\
\hline & Reference & Test & t-test p-value & Reference & Test & t-test p-value \\
\hline Depth (cm) & $84 \pm 0.70$ & $39 \pm 0.16$ & 0.02 & $128 \pm 2.0$ & $130 \pm 1.7$ & ns \\
\hline Water temperature $\left({ }^{\circ} \mathrm{C}\right)$ & $26 \pm 1.28$ & $27 \pm 1.34$ & ns & $32 \pm 3.80$ & $31 \pm 3.10$ & ns \\
\hline Air temperature $\left({ }^{\circ} \mathrm{C}\right)$ & $29 \pm 3.08$ & $29 \pm 3.02$ & ns & $29 \pm 2.92$ & $31 \pm 2.39$ & ns \\
\hline Conductivity $(\mu \mathrm{s} / \mathrm{cm})$ & $106 \pm 76.67$ & $381 \pm 578$ & 0.02 & $145 \pm 115$ & $636 \pm 1124$ & 0.01 \\
\hline TDS (mg/L) & $79 \pm 2.27$ & $95 \pm 1.75$ & ns & $101 \pm 49.72$ & $157 \pm 426$ & ns \\
\hline $\mathrm{pH}$ & $7 \pm 0.60$ & $7.21 \pm 0.86$ & ns & $7.24 \pm 0.99$ & $6.84 \pm 0.68$ & ns \\
\hline $\mathrm{DO}(\mathrm{mg} / \mathrm{L})$ & $6 \pm 1.77$ & $6.83 \pm 0.38$ & ns & $6.68 \pm 2.17$ & $6.88 \pm 2.34$ & ns \\
\hline $\mathrm{BOD}_{5}(\mathrm{mg} / \mathrm{L})$ & $2.57 \pm 0.88$ & $3.72 \pm 1.73$ & 0.03 & $1.3 \pm 1.44$ & $1.59 \pm 1.45$ & ns \\
\hline Turbidity (FAU) & $9 \pm 15.32$ & $14.4 \pm 15.6$ & ns & $22 \pm 21.2$ & $65 \pm 18.04$ & 0.04 \\
\hline TSS (mg/L) & $6.73 \pm 8.94$ & $9.60 \pm 9.2$ & ns & $13.2 \pm 11.87$ & $40 \pm 64.90$ & 0.01 \\
\hline Nitrate-nitrogen (mg/L) & $0.61 \pm 0.4$ & $0.80 \pm 0.6$ & ns & $0.68 \pm 0.43$ & $1.26 \pm 1.20$ & ns \\
\hline Orthophosphate (mg/L) & $0.3 \pm 0.2$ & $0.32 \pm 0.4$ & ns & $0.18 \pm 0.13$ & $0.30 \pm 0.37$ & 0.04 \\
\hline Ammonia-nitrogen (mg/L) & $0.66 \pm 0.83$ & $0.43 \pm 0.33$ & ns & $0.72 \pm 0.2$ & $0.75 \pm 0.57$ & 0.04 \\
\hline Chlorophyll a $(\mu \mathrm{g} / \mathrm{L})$ & $4.79 \pm 4.38$ & $4.0 \pm 3.30$ & ns & $10.2 \pm 6.78$ & $8.71 \pm 6.22$ & .030 \\
\hline
\end{tabular}

ns, Non significant.
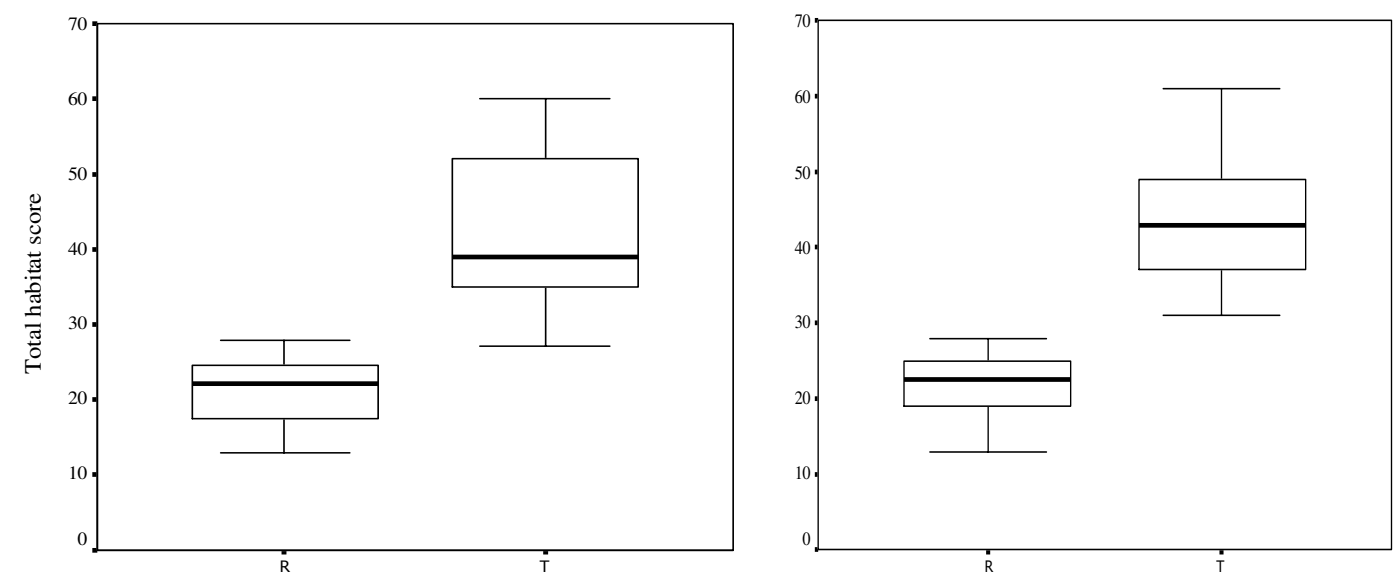

Figure 2. Box plot of total human disturbance score of reference and test sites for the cool (a) and hot (b) seasons

that the taxa were generally more influenced by the season than by the wetland type.

\section{Selection of metrics}

Thirteen metrics were chosen as candidates because they demonstrated a DE of more than $50 \%$ in the cool and hot seasons. Almost all of the metrics showed a relatively moderate $\mathrm{DE}$, and the total taxa and total genera richness performed the best overall. A correlation analysis was performed on these 13 metrics to exclude redundant metrics from the index. Those metrics with a correlation coefficient $>0.85$ were considered redundant and were not used together in any index formulation. The total taxa richness was redundant with the total genera and predator taxa, whereas the Ephemeroptera $(E)$, Trichoptera $(\mathrm{T})$, and Odonata $(\mathrm{O})$ taxa metric (ETO taxa) was redundant with Odonata taxa, Odonata genus, OT taxa, and Beck's biotic index (Table 2). From this analysis, 8 core metrics were identified as potential metrics for calibration of matrics and index development. The total human disturbance score correlated with most of the metrics, and nitrate-nitrogen, turbidity and TSS were also correlated with some of the metrics $(p<0.05)$.

\section{Calibration of metrics and index development}

The 8 core metrics (total taxa, ETO taxa, Crustacea + Mollusca (CRMOL) taxa, Beck's biotic index, predator taxa, scrapers taxa, sprawler taxa and swimmer taxa) 
Table 2. Pearson correlation matrix of benthic macroinvertebrates metrics in the reference sites.

\begin{tabular}{|c|c|c|c|c|c|c|c|c|}
\hline Metric & Total taxa & Total genera & Climber taxa & CRMOL taxa & ETO taxa & Odonata genus & OT taxa & Odonata taxa \\
\hline Total genera & $1.00 * a$ & & & & & & & \\
\hline Climber taxa & $0.40^{* *}$ & $0.41^{* *}$ & & & & & & \\
\hline CRMOL taxa & $0.52^{* *}$ & $0.53^{*}$ & 0.20 & & & & & \\
\hline ETO taxa & $0.77^{\star \star}$ & $0.76^{\star *}$ & $0.68^{\star *}$ & $0.24^{*}$ & & & & \\
\hline Odonata genus & $0.60^{* *}$ & $0.61^{* *}$ & $0.75^{\star *}$ & 0.20 & $0.89^{* * a}$ & & & \\
\hline OT taxa & $0.71^{* *}$ & $0.71^{* *}$ & $0.73^{\star *}$ & $0.26^{*}$ & $0.96 * * a$ & $0.94^{\star \star a}$ & & \\
\hline Odonata taxa & $0.60^{* *}$ & $0.61^{* *}$ & $0.75^{\star *}$ & 0.21 & $0.88^{\star \star a}$ & $1.00^{\star * a}$ & $0.94^{\star \star a}$ & \\
\hline Predator taxa & $0.90^{* * a}$ & $0.90^{\star * a}$ & $0.39^{* *}$ & $0.28^{*}$ & $0.71^{* *}$ & $0.65^{\star *}$ & $0.67^{\star \star}$ & $0.65^{* *}$ \\
\hline Beck's biotic index & $0.71^{* *}$ & $0.72^{* *}$ & $0.43^{\star *}$ & 0.14 & $0.87^{* *}$ & $0.82^{* *}$ & $0.85^{\star \star}$ & $0.81^{\star *}$ \\
\hline Metric & Predator taxa & Scraper taxa & Sprawler taxa & Swimmer taxa & & & & \\
\hline Beck's biotic index & $0.74^{\star *}$ & 0.14 & $0.58^{* \star}$ & $0.41^{* *}$ & & & & \\
\hline Swimmer taxa & 0.81 ** & $0.25^{*}$ & $0.58^{\star *}$ & & & & & \\
\hline Sprawler taxa & $0.612^{* *}$ & $0.79^{* *}$ & & & & & & \\
\hline Scraper taxa & $0.32^{* *}$ & & & & & & & \\
\hline
\end{tabular}

Marked correlations are significant ${ }^{\mathrm{a}}$ Redundancy metrics; ${ }^{*} p<0.05 ;{ }^{* *} p<0.01$.

were transformed into unit-less scores using two methods (the DRQ1 and CAU methods). The category scoring range and descriptive statistics for all of the core metrics for each season are shown in Tables 3 and 4 . The core metrics score values were entered in each index trial model calculation. The models showed that only 7 core metrics (predator taxa was eliminated as a core metric) had the strongest DEs for both the DRQ1 and CAU indexes in both seasons. The box plots supported the ability of final indexes to discriminate the reference and test site populations, as shown in Figure 3. Pearson's correlation analysis indicated that both of the indexes were negatively correlated with human disturbance score (DRQ1 = -0.57, CAU = -0.62). In addition, we also found that both index scores were negatively correlated with increasing water temperature $(r>-0.244, p<$ $0.05), \mathrm{BOD}_{5}(r>-0.28, \mathrm{p}<0.05)$, nitrate-nitrogen $(r>-0.29, p<0.05)$, TSS $(r>-0.27, p<0.05)$ and turbidity $(r>-0.283, p<0.05)$. Furthermore, the CAU index was negatively correlated with the conductivity $(r=-0.28, p<0.05)$, whereas the DRQ1 index was negatively correlated with the water temperature $(r=-0.24, p<0.05)$.

\section{Wetland bioassessment}

The assessment was divided into 5 categories based on the range of index values among all of the reference sites. A value greater than or equal to the $75^{\text {th }}$ percentile of that range was rated as "Very Good", and a value greater than or equal to the $25^{\text {th }}$ percentile of that range was rated as "Good". Index values falling below the $25^{\text {th }}$ percentile were rated as "Fair", "Poor" or "Very Poor" (Table 5). These ordination rating categories were used to assign impairment ratings to all of the sampling sites. The results for the DRQ1 and CAU methods were similar. Approximately $85 \%$ of the reference sites were "Very Good" or "Good", whereas most of the test sites were categorized as "Fair" (69\%) by the DRQ1 index score. A much lower percentage of sites were rated as "Fair" by the CAU index score (20.6\%), as shown in Figure 4. In addition, the rating similarity for the all sampling sites between the DRQ1 and CAU scoring was $55 \%$.

\section{DISCUSSION}

\section{Physicochemical parameters and habitat characteristics}

The results showed that the biological index scores were negatively correlated (that is, the biological condition decreased) with increases in water temperature, biochemical oxygen demand, 
Table 3. Descriptive statistic and score for the core metric for the cold season.

\begin{tabular}{lcccccccc}
\hline \multirow{2}{*}{ Metrics } & \multicolumn{4}{c}{ Descriptive statistics } & \multicolumn{3}{c}{ Categorical scoring rage } \\
\cline { 2 - 9 } & Minimum & 25th & median & 75th & Maximum & $\mathbf{5}$ & $\mathbf{3}$ & $\mathbf{1}$ \\
\hline Total taxa & 47 & 24 & 29 & 35 & 47 & $\geq 24$ & $12-23$ & $<12$ \\
ETO taxa & 1 & 5 & 7 & 9 & 21 & $\geq 5$ & $3-4$ & $<3$ \\
CRMOL taxa & 4 & 12 & 13 & 14 & 20 & $\geq 12$ & $6-11$ & $<6$ \\
Beck's Biotic Index & 1 & 4 & 5 & 5 & 10 & $\geq 4$ & $3-2$ & $<3$ \\
Predator taxa & 11 & 12 & 16 & 19 & 25 & $\geq 12$ & $6-11$ & $<6$ \\
Scraper taxa & 2 & 4 & 5 & 6 & 9 & $\geq 4$ & $2-3$ & $<2$ \\
Sprawler taxa & 2 & 7 & 9 & 10 & 18 & $\geq 7$ & $4-6$ & $<4$ \\
Swimmer taxa & 5 & 8 & 10 & 11 & 16 & $\geq 8$ & $4-7$ & $<4$ \\
\hline
\end{tabular}

Table 4. Descriptive statistic and score for the core metric for the hot season.

\begin{tabular}{lcccccccc}
\hline \multirow{2}{*}{ Metrics } & \multicolumn{4}{c}{ Descriptive statistics } & \multicolumn{3}{c}{ Categorical scoring rage } \\
\cline { 2 - 9 } & Minimum & $\mathbf{2 5}^{\text {th }}$ & median & $\mathbf{7 5}^{\text {th }}$ & Maximum & $\mathbf{5}$ & $\mathbf{3}$ & $\mathbf{1}$ \\
\hline Total taxa & 20 & 25 & 33 & 40 & 55 & $\geq 20$ & $13-19$ & $<13$ \\
ETO taxa & 3 & 6 & 9 & 13 & 16 & $\geq 6$ & $3-5$ & $<3$ \\
CRMOL taxa & 4 & 9 & 15 & 19 & 30 & $\geq 9$ & $5-8$ & $<5$ \\
Beck's Biotic Index & 1 & 4 & 5 & 6 & 9 & $\geq 4$ & $3-2$ & $<3$ \\
Predator taxa & 8 & 11 & 16 & 19 & 31 & $\geq 11$ & $6-10$ & $<6$ \\
Scraper taxa & 1 & 4 & 6 & 8 & 10 & $\geq 4$ & $3-2$ & $<2$ \\
Sprawler taxa & 3 & 6 & 8 & 12 & 14 & $\geq 6$ & $3-5$ & $<3$ \\
Swimmer taxa & 5 & 9 & 11 & 12 & 21 & $\geq 9$ & $5-8$ & $<5$ \\
\hline
\end{tabular}
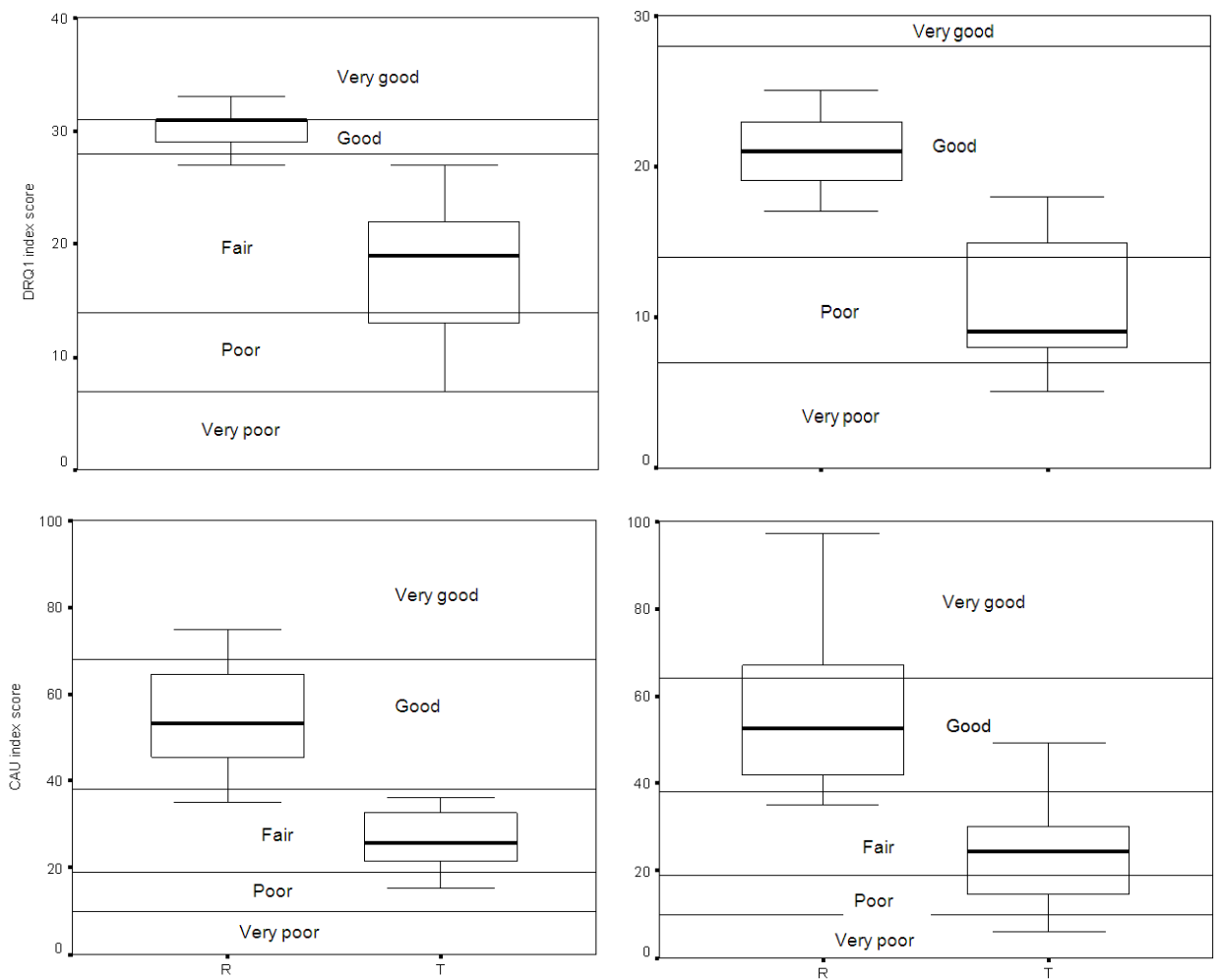

Figure 3. Box plot comparing the index scores (DRQ1 and CAU) between the population of reference and test sites for the cool (a) and hot (b) seasons. 


\section{Reference sites $\quad$ Test sites}
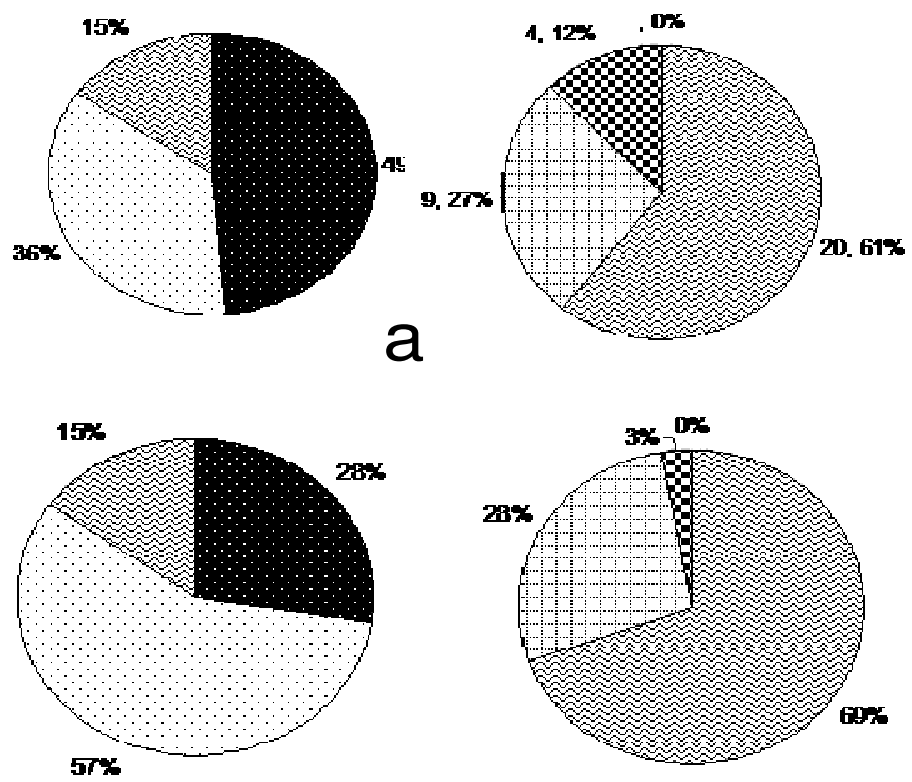

Very good a Good aFair aPoor uVery poor

b

Figure 4. Pie diagram showing the percentage of narrative assessment of reference and test sites between DRQ1 (a) and CAU (b) methods.

Table 5. Definition of narrative assessment using index value based on final index model.

\begin{tabular}{lccccc}
\hline Narrative & $\begin{array}{c}\text { Percentile of reference } \\
\text { index value }\end{array}$ & \multicolumn{2}{c}{ DRQ1 index score } & \multicolumn{2}{c}{ CAU index score } \\
\cline { 3 - 6 } assessment & $\geq 75^{\text {th }}$ & cool & hot & cool & hot \\
\hline Very good & $\geq 25^{\text {th }}$ & 32 & 31 & $64-100$ & $68-100$ \\
Good & $<25^{\text {th }}$ & $28-31$ & $28-30$ & $44-63$ & $38-67$ \\
Fair & - & $14-27$ & $14-27$ & $22-43$ & $19-37$ \\
Poor & - & $7-13$ & $7-13$ & $11-21$ & $10-18$ \\
Very poor & $<7$ & $<7$ & $<11$ & $<10$ \\
\hline
\end{tabular}

nitrate-nitrogen concentration, level of TSS and the turbidity. During this present study, most of the impaired sites were influenced by hydrologic modifications, such as ditching, filling and man-made dikes, and by vegetative modifications, such as the clearing and removal of vegetation. As a result of these activities, there were increases in the conductivity, turbidity, TSS, $\mathrm{BOD}_{5}$ and nutrient levels in the test sites relative to the reference sites (Dauer et al., 2000). In general, the level of chlorophyll $a$ is greater at test sites than reference sites; however, we found that the chlorophyll a level was often higher in the reference sites in our study. This may be because of the road construction and removal of vegetation, with increases in the turbidity as a result of increased deposition due to the nearby activity. The total habitat disturbance scores were strongly negatively correlated with 23 metrics that decrease with the level of impairment. We found that the total human disturbance scores were strongly negatively correlated with the biological index score which agree with the finding of Kashian and Buton (2000), Blocksom et al. (2002), Yimer and Mengistou (2009). We also found a high degree of tree cover in the riparian zone and the presence of submerged plants in the reference sites, with Trichoptera and Ephemeroptera exhibiting greater richness and biodiversity at the references sites than the impaired sites. These findings support the results of previous studies, such as those by Battle and Golladay (1999), Chipps et 
al. (2006) and Takamura et al. (2009).

\section{Calibration of the metrics list and index development}

From an original group of 63 metrics, only 7 core metrics met the strict criteria of a low within-site variability for the reference sites: the total taxa, ETO taxa, CRMOL taxa, Beck's biotic index, scrapers taxa, sprawler taxa and swimmer taxa. These metrics were able to distinguish the impacted sites from the reference sites and are candidate metrics for use as indicators of long-term impacts on water quality in wetlands.

The core metrics that represent the ecological characteristics for this study include the species richness, tolerance, the trophic level and the habitat structure of the benthic macroinvertebrate assemblage. Core metrics are more robust when composed of 8 to 12 metrics, and they should be selected from different categories (taxa richness, tolerance/ intolerance, trophic structure and functional feeding group and individual heath) that reflect the responses to changes in the physical, chemical, and biological integrity of the wetlands and surrounding landscape (USEPA, 2002).

Three richness measures (Total taxa, ETO taxa, CRMOL taxa) were retained as components of the final index. Total taxa, ETO and CRMOL have been used as indicators of environmental disturbances in wetlands in many US states (Burton et al., 1999; Florida DEP, 2000; Kashian and Burton, 2000; USEPA, 2002). In this study, we found that Ephemeroptera and Trichoptera were sensitive indicators of the water quality, with lower proportions at impacted sites.

This finding was supported by the study of Kashian and Burton (2000). We found that only Beck's biotic index was representative of differences in the tolerance index between the reference and test sites. The moderate organic pollution in wetlands may be sufficient to increase the food resources for some of the moderately tolerant benthic macroinvertebrates without causing negative impacts, therefore resulting in greater richness (Kashian and Burton, 2000).

The metrics based on the species composition showed no impact of degradation, supporting the studies in many US states (USEPA, 2002), studies that lacked candidate composition matrices for wetlands. Metrics based on functional feeding groups are useful measures of the trophic and functional composition and include measures of the relative abundance of scrapers a surrogate for ecosystem attributes: balance between autotrophy and heterotrophy (Cummins et al., 2005).

The metrics that are most significantly related to the human disturbance scores and to chemical factors are total taxa, Beck's biotic index, ETO taxa and swimmer taxa. Relationships between Biotic index and environmental variables (chemical factors and human disturbance score) showed significant different for the CRMOL taxa, Scraper taxa and Sprawler taxa $(p<0.05)$.
The index score of the DRQ1 and the CAU methods performed well in the assessment of the pollution status of the study sites and showed results similar to those of previous Thai river and stream studies (Boonsoong et al., 2009, Getwongsa et al., 2010; Uttaruk et al., 2011). The CAU index score showed a relatively higher correlation with the human disturbance score, indicating that this method was more consistent than the DRQ1 index score.This result is consistent with the conclusion of Blocksom (2003) that the CAU method performed the best overall for the Macroinvertebrate Biotic Integrity Index. Furthermore, the CAU scoring method was identified as being less variable among reference lakes in Florida than a DRQ1 method based on similar scoring threshold values (Florida DEP, 2000). Blocksom (2003) evaluated the effect of different metric scoring methods on the performance of the Macroinvertebrate Biology Integrity Index and found that the CAU method had better performance for the measures of index variability and had less variable measurements; however, it has also been reported that using all of the sites for setting the expectations was advantageous in reducing the index variability. In addition, Blocksom and Johson (2009) suggested that using the full distribution of sites to set the thresholds for scoring is more practical than using reference and test sites to set the expectations for each metric because there are relatively few reference sites available.

\section{Conclusion}

The development of a multi-metric approach based on benthic macroinvertebrates appears to be feasible for the wetlands of northeastern Thailand. The 7 most suitable metrics were used to calculate index score. The patterns of changes in the benthic macroinvertebrate assemblage were reflected in the responses to human impact. Although our results suggest that the index could be an effective tool for the management, prioritization, and monitoring of these wetlands, we recommend that these protocols be tested in further studies and that the testing and validation of our index should be performed in other regions.

\section{ACKNOWLEDGMENTS}

This work was supported by the TRF/BIOTEC Special Program for Biodiversity Research and Training Program grant BRT T352062. The authors extends their thanks to KKU Publication Clinic for providing professional editing service from American Journal Experts.

\section{REFERENCES}

APHA AWWA, WPCF (1998). Standard method for examination of water and wastewater $20^{\text {th }}$ ed. American Public Health Association. 
American Water Work Association and Water Pollution Control Federation, Wachington, DC.

Barbour MT, Gerritsen J, Snyder BD, Stribling JB (1999). Rapid bioassessment protocols for use in streams and wadable rivers: periphyton, benthic macroinvertebrates and fish. $2^{\text {nd }}$ ed. US Environmental Protection Agency, Washington, DC.

Battle J, Golladay SW (1999). Water quality and aquatic macroinvertebrates in 3 types of reference Limesink wetlands in southwest Georgia. Proceedings of the 1999 Georgia Water Resources Conference, Hatcher KJ editor, Institute Ecology, The University of Georgia, Athens, Georgia. pp. 439-442.

Blocksom KA, Kurtenbach JP, Klemm DJ, Fulk FA, Cormier SM (2002). Development and evaluation of the lake Macroinvertebrate Integrity Index (LMII) for New Jersey lakes and reservoirs. Environ. Monit. Assess. 77(3): 311-333.

Blocksom KA (2003). A Perormance comparision of metric scoring methods for a Multmetric index for Mid-Atlandtic Highlands streams. Environ. Manag.31: 670-682.

Blocksom KA, Jhonson BR (2009). Development of a regional macroinvertebrate index for large river bioassessment. Ecol. indic. pp.313-328.

Boonsoong B, Sangpradub N, Barbour MT (2009). Development of Rapid Bioassessment Approaches Using Benthic Macroinvertebrates for Thai Streams. Environ. Monit. Assess. 155: 129-147.

Burton TM, Uzarski DG, Gathman JP, Genet JA, Keas BE, Stricks CA (1999). Development of a preliminary invertebrate index of biotic integrity for lake Huron coastal wetlands. Wetlands. 19(4): 869-882.

Chipps SR, Hubbard DE, Werlin KB, Haugerud NJ, Powell KA, Thompson PJ, Johnson T (2006). Assosication between wetland disterburbance and biological attributes in floodplain wetlands. Wetlands. 26(2): 497-508.

Cummins KW, Merrit RW, Andrade PCN (2005). The use of invertebrate functional groups to characterize ecosystem attributes in selected streams and river in south Brazil. Stu.Neot.Fau.Environ. 40(1): 69-89.

Dauer DM, Ranasinghe JA, Weisberg SB (2000). Relationships between benthic community condition water quality, sediment quality, nutrient loads, and land use patterns in Chesapeake Bay. Estuaries. 23(1): 80-96.

Davis J, Horwitz P, Norris R, Chessman B, McGuie M, Sommer B (2006). Are river bioassessment methods using macroinvertebrates applicable to wetlands? Hydrobiologia 572:115 -128.

Florida DEP (2000). Development of Lake Condition Indexes (LCl) for Florida. Florida Department of Environmental Protection (Florida DEP), Nonpoint Source Bioassessment Program, Orlando, Florida.

Flotemersch JE, Stribling JB, Paul MJ (2006). Concepts and approaches for the bioassessment of non-wadable streams and river. EPA 600-R-06-127. US Envionmental Protection Agency, Cincinnatia, Ohio.

Galbrand C, Lemieux IG, Cote R, Verma M (2007). Assessment of Constructed wetlands biological integrity using aquatic macroinvertebrates. J. Biol. Sci. 7(2):52-65.

Getwongsa P, Hanjavanit C, Sangpradub N (2010). Impacts of agricultural land use on stream benthic macroinvertebrates in tributaries of the Mekong River, northeast Thailand. AES BIOFLUX. 2(2): $97-112$.

Heino J (2000). Lenthic macroinvertebrates assessblage structure along gradients in Spatial heterogeneity, habitat size and water chemistry. Hydrobiologia 418:229-242.

Kerans BL, Karr JR (1994). A biotic index of biotic integrity (B-IBI) for rivers of the Tennessee Valley. Ecol. Appl. 4:768-785.

Kashian RD, Burton MT (2000). A comparision of macroinvertebrates of two Great Lakes coastal wetlands: testing potential metrics for an Index of ecological integrity. J. Great Lakes Res. 26(4):460-418.

Kazancı N, Gökçe D, Girgin S, Dügel M (2003). Distribution of benthic macroinvertebrates in relation to physico-chemical properties in the Köyceğiz-Dalyan Estuarine Channel System (MediterraneanSea,Turkey). Indian. Hou. Mar. Sci. 32(2):141-146.

Marchetti MP, Garr M, Smith ANH (2008). Evaluating wetland restoration success using aquatic macroinvertebrate assessblages in the SacramentoValley, California. Restor. Ecol. 18(4):457-466.
McCune B, Mefford MJ (2006). PC-ORD. Mutivariate Analysis of Ecological Data. Version 5. MjM Software, Gleneden Beach, Oregon, USA.

Mose CJ, Lianfang Y, Lixin T (1994). Aquatic insects of China useful for monitoring water quality. Hohai University Press, Nanjing China.

Morse JC, Bae YJ, Munkhjargal G, Sangpradub N, Tanida K, Vshivkova TS, Wang B, Yang L, Yule CM (2007). Freshwater biomonitoring with macroinvertebrates in East Asia. Front. Ecol. Environ. 5:33-42.

Mustow SE (2002). Biological monitoring of river in Thailand: use and adaptation of BMWP score. Hydrobiologia 479(1):191-229.

Office of Environmental Policy and Planning (2002). National report on the implementation of convention on wetlands. Ministry of science, technology and environment, Bangkok, Thailand.

Pagdee A, Homchuen S, Sangpradub N, Hanjavanit C, Uttharak P (2007). Biodiversity and Economic value of wetland resources at Nong Han, Udonthani province, northeast Thailand. Natural History Bull. Siam Soc. 55(2):323-339.

Reynoldson TB, Bailey RC, Day KE, Norris RH (1995). Biological guidelines for freshwater sediment based on BEnthic Assessment of SedimenT (BEAST) using a multivariate approach for predicting biological state Australian. J. Ecol. 20(1):198-219.

Sangpradub N, Boonsoong B (2006). Identification of freshwater invertebrates of the Mekong River and tributaries. Mekong River Commission, Vientiane.

Smith MJ, Kay WR, Edward DHD, Papas PJ, Richardson KS, Simpson JC, Pinder AM, Cale DJ, Horwitz HJ, Davis JA, Yung FH, Norris RH, Halse HA (1999). AusRivAS: using macroinvertebrates to assess ecological condition of rivers in Western Australia. Freshwater Biol. 41(2):269-282.

Stribling JB, Jessup BK, Gerritsen J (2000). Development of biological and physical habitat criteria for Wyoming streams and their use in the TMDL process. Tetra Tech, Inc., Maryland.

Studinski JM, Grubbs AS (2007). Environmental factors affecting the distribution of aquatic invertebrates in temporary ponds in Mammoth Cave National Park, Kentucky, USA. Hydrobiologia 575(1):211-220.

Takamura N, Ito T, Ueno R, Ohtaka A, Wakana I, Nakagawa M, Ueno $\mathrm{Y}$, Nakajima H (2009). Environmental gradients determining the distribution of benthic macroinvertebrates in Lake Takkobu, Kushiro wetland, northern Japan. Ecol. Res. 24:371-381.

Tarr TL, Baber MJ, Babbitt T (2005). Macroinvertebrate community structure across a wetland hydroperiod gradient in southern New Hampshire, USA. Wetland. Ecol. Manag. 13:321-334.

Tetra Tech (2000a). Ecological Data Application System (EDAS): A User's Manual. Prepared by Tetra Tech, Inc., Owings Mill, Maryland.

Tetra Tech (2000b). A stream condition index for West Virginia wadeable streams. Tetra Tech, Inc, Maryland.

Thorne R, Williams $P$ (1997). The response of benthic macroinvertebrates to pollution in developing countries: a multimetric system of bioassessment. Freshwater Biol. 37:671-686.

USEPA (2002). Methods for Evaluating Wetland Condition: Introduction to wetland Biological Assessment. Office of Water, US Environmental Protection Agency, Washington, DC. EPA-822-R-02-014.

USEPA (2003). Methods for Evaluating Wetland Condition: Wetland Biological Assessment Case Studies. Office of Water, US Environmental Protection Agency, Washington, DC. EPA-822-R-03013.

Uttaruk $\mathrm{P}$, Voharndee $\mathrm{P}$, Jusanit $\mathrm{P}$, Bunya-adunyakit $\mathrm{P}$, Suriya $\mathrm{S}$, Jaengjaithun T, Nittaya K, Sangpradub N (2011). Development of biotic index based on rapid bioassessment approaches using benthic macroinvertebrates for Chi and Mun headwater streams, northeast Thailand. AES BIOFLUX 3(1):29-42.

Wilcox DA, Meeker JE, Hudson PL, Armitage BJ, Black MG, Uzarski DG (2002). Hydrologic variability and the application of index of bio tic integrity and the application of index of biotic integrity metrics to wetlands: a great lakes evolution. Wetlands 22(3):588-615.

Yimer HD, Mengistou S (2009). Water Quality Parameters and Macroinvertebrates Index of Biotic Integrity of the Jimma Wetlands, Southwestern Ethiopia. J. Wet. Ecol. 3:77-93. 